\title{
Distal spinal muscular atrophy type 3
}

INSERM

\section{Source}

INSERM. (1999). Orphanet: an online rare disease and orphan drug data base. Distal spinal muscular atrophy type 3. ORPHA:139547

Distal spinal muscular atrophy type 3 is a rare neuromuscular disease characterized by progressive muscular weakness and atrophy predominantly affecting distal parts of limbs, later involvement of proximal and trunk muscles with marked hyperlordosis and late diaphragmatic dysfunction. 